\title{
REUNIÓES CIENTfFICAS
}

\section{CENTRO DE ESTUDOS FRANCO DA ROCHA PRESIDENTE: DR. DARCY MENDONÇA UCHOA \\ Sessão ordinária - 21 maio 1945}

Cálcio coloidal intra-raqueano na epilepsia. Dr. José Botiglieri.

O A., que já usou a prata coloidal em 11 epilépticas, usou agora o cálcio coloidal também por via raqueana lombar. Escolheu 10 epilépticas crônicas, com 
rebaixamento mental e freqüentes crises, apesar do uso constante de barbitúricos. Foram feitas 6 a 14 injeções (de 1 c.c. a primeira e de 2 c.c. as seguintes) para cada doente. As reações - febre, cefaléia, raquialgia e vômitos - ainda que intensas, foram passageiras e não necessitaram medicação especial. Desprezando as modificaçōes inferiores a 20\%, no número de ataques, foi verificado que 5 doentes melhoraram durante o tratamento, conseguindo redução de $25 \%, 27 \%, 48 \%, 60 \%$ e $61 \%$ no número de acessos; em três doentes não houve modificação quanto às crises; uma doente piorou de $23 \%$; num caso, por várias circunstâncias, não se completaram as modificações durante o tratamento. Nos meses seguintes ao tratamento (de 2 a 5 meses, conforme o caso), houve melhora em 4 casos, de $90 \%$. $60 \%, 58 \%$ e $54 \%$; piora em 2 , de $68 \%$ e $26 \%$; em 4 casos não houve modificação apreciável das crises, comparada com o período anterior ao tratamento. Dessas doentes, 5 apresentavam freqüente agitação psicomotora e, em 4 delas, houve redução dessa agitação de $77 \%, 75 \%, 74 \%$ e $60 \%$; na restante, houve piora de $21 \%$.

Sôbre um caso de esquizofrenia paranóide. Dr. Caetano Trapé.

Tratava-se de uma doente com 42 anos, branca, professora de piano, inter nada no Hospital em junho 1942. O desenvolvimento somatopsíquico da paciente foi normal; sempre foi alegre, expansiva e possuia alto conceito de si mesma e do meio em que vivia. Há 7 anos, começou a apresentar idéias supervalorizadoras de grandeza. Fêz convulsoterapia (eletrochoque e cardiazol) sem melhoras; com a insulinoterapia, melhorou um pouco. Ưltimamente (1945), três anos após a internação, continuava a apresentar a mesma sintomatologia delirante de fundo paranóide. Tornou-se implicante, raivosa, briguenta, pondo sua atividade pessoal a serviço das idéias delirantes. Como o quadro mental não regredisse, foi indicada a leucotomia a Egas Moniz, o que foi recusado pela família da paciente, tendo esta pedido aos parentes que a retirassem do hospital; no dia em que deveria ter alta a pedido, a paciente teve violenta reação delirante e de agitação, agredindo a todos. O caso foi relatado para ressaltar a persistência dos fenômenos produ. tivos delirantes de fundo paranóide, que pouco se beneficiaram com as terapêuticas habituais, hem como para mostrar a cronicidade do caso e sua evolução para o defeito psíquico, para as seqüelas do processo esquizofrênico. Acentuou o A. a resistência dêsses casos processuais às terapêtuticas usuais $e$ insistiu sôbre a necessidade da criação de um serviço que atenda mais às formas agudas da doença, isto é, as mais influenciáveis pelos tratamentos psiquiátricos.

\section{Sessões extraordinárias - 25 e 29 maio e 1 junho 1945}

Estas sessões extraordinárias do Centro de Estudos Franco da Rocha, realizadas conjuntamente com a Seç̧ão de Neuro-Psiquiatria da Associação Paulista de Medicina e o IDORT (Instituto de Organização Racional do Trabalho), foram convocadas para as seguintes conferências do Prof. Emilio Mira y Lopez, que discorreu sôbre: "Influência das diversas escolas psicológicas na psiquiatria"; "Elementos para o prognóstico da esquizofrenia" e "Os quatro gigantes da alma: $a$ ira, o mêdo, o amor $e$ o dever".

\section{Sessões extraordinárias - 25, 26 e 28 junho 1945}

Em conjunto com o Serviço de Endocrinologia da Santa Casa de Misericórdia de São Paulo, com a Secção de Neuro-Psiquiatria da Associação Paulista de Medicina e com a Sociedade de Medicina e Cirurgia de São Paulo, o Centro de Estudos Franco da Rocha fêz realizar quatro sessões extraordinárias, nas quais o Dr. Arnaldo Raskovsky pronunciou as seguintes conferências: " $O$ acesso epiléptico como uma rcação neurótica atual", "Fatores psicogênicos na sindrome adiposo.. genital", "A formação psicanalítica. Considerą̧ões para o desenvolvimento do 
movinenio psicanalitico na América Latina" e "Considerações psicossomáticas sôbre o descnvolvimento sexual da crianca".

PRESIDENTE: DR. JOSÉ P. G. D'ALAMBERT

Sessão ordinária - 27 julho 1945

Uin caso de sindrome frontal arbitária. Drs. Anibal Silveira e Mario Robortella.

Os AA. observaram um caso que, à primeira vista, apresentava um quadro histérico, mas o exame neurológico revelou a existência de outros sinais indicativos de lesão orgânica assestada na porção orbitária do lobo frontal. Devido à idade do paciente e a outras condições, foi admitida a etiologia arteriosclerótica.

Infantilismo geral de origem ovariana. Dr. José P. G. d'Alambert.

O A. faz um apanhado geral sôbre o infantilismo, destacando sua etiopatogenia e sua classificação. Aborda os casos de origem gonadal, separando o eunucoidismo e estudando, particularmente, a contribuição recente trazida por Varnay, Albright e colaboradores a respeito de casos de infantilismo geral atribuídos a origem ovariana. Estuda, também, os casos, descritos por Turner como infantilismo pterigonucal. Finalmente, apresenta um caso próprio, estudado clínica, radiológica e anatômicamente.

\section{Sessão ordinária - 31 agôsto 1945}

Considerações sôbre dois casos de gagueira. Dr. Antonio Branco Lefèvre.

Este trabalho vem publicado no presente número desta revista.

Um caso de esquizofrenia tratado pela leucotomia. Drs. Antero Barradas Barata e Antonio Carlos Barreto.

Os AA. relataram um caso de esquizofrenia, que, tratado pela leucotomia, apresentou remissão total, embora tardia. 